\title{
积极正面引导 儿童健康成长
}

任丽蓉

河南大学金明校区

DOI:10.32629/er.v2i9.2036

[摘 要] 党的十八大以来, 以习近平同志为核心的党中央站在党和国家事业发展薪火相传、后继有人的战略高度,高度重视青 少年工作, 亲切关怀青少年和儿童的健康成长。

[关键词] 积极; 引导; 儿童; 健康成长

青年是祖国的未来, 民族的希望, 重视青年就是重视未 来。习近平总书记在庆祝中国共产党成立95周年大会上强 调: “全党要关注青年、关心青年、关爱青年, 倾听青年心声, 做青年朋友的知心人、青年工作的热心人、青年群众的引路 人。”他要求各级党委和政府要充分信任青年、热情关心青 年、严格要求青年, 为青年驰骋思想打开更浩瀚的天空, 为青 年实践创新搭建更广阔的舞台, 为青年塑造人生提供更丰富 的机会, 为青年建功立业创造更有利的条件。

2014年5月4日, 习近平在北京大学师生座谈会上鼓励青 年们要积极投身到祖国建设中。“现在在高校学习的大学生 都是 20 岁左右, 到 2020 年全面建成小康社会时, 很多人还不 到30岁; 到本世纪中叶基本实现现代化时, 很多人还不到 60 岁。也就是说, 实现 “两个一百年” 奋斗目标, 你们和千千万 万青年将全过程参与。”

新时代广大青年拥有广阔发展空间, 承载着伟大时代使 命。要承担起光荣使命, 青年人当先立鸿鹄之志。只有把人 生理想融入国家和民族的事业中, 才能最终成就一番事业。 习近平在北京大学师生座谈会上强调, “青年的价值取向决 定了未来整个社会的价值取向, 而青年又处在价值观形成和 确立的时期, 抓好这一时期的价值观养成十分重要。这就像 穿衣服扣扣子一样, 如果第一粒扣子扣错了, 剩余的扣子都 会扣错。人生的扣子从一开始就要扣好。”

少年儿童是祖国的花朵, 是中华民族的未来和希望。习 近平将少年儿童比作 “小树苗”, 在习近平看来, 少年儿童的 成长要坚持品德为先, 他曾寄语全国各族少年儿童 “要从小 学习做人”。“现在把自己的品德培育得越好, 将来人就能做 得越好。”

在儿童群体中存在着这样一种现象: 教师制定一项规则, 并明确提出它的惩罚方式, 但有些儿童却故意触犯这条规则, 从而接受惩罚, 甚至在接受惩罚的过程中, 带有一种满足感。

有这样一个更为具体的事例。每天中午吃饭前, 幼儿需 要排队洗手, 洗完手用完毛巾后大家纷纷离开, 而教师还需 将毛巾架推到阳台上进行晾晒。但与此同时, 教师还要去为 幼儿打饭、推餐车, 甚至还有些幼儿喜欢玩水, 故意在洗手时 磨蹭时间, 耽误了吃饭, 这样一来教师就不能够在所有幼儿 洗完手后按时将毛巾架推出。于是, 老师想到了一种方法,
规定每天中午全班最后洗完手的那位幼儿负责将毛巾架推 出, 这实际上也是督促幼儿尽快洗手, 不磨蹭时间。这时, 出 现了一种非常有趣的现象。有一个幼儿每天中午故意在洗手 时磨时间, 就算教师催促也不以为然, 洗手洗好多遍, 当其他 幼儿纷纷离开, 他便自然而然地成为了最后一个。教师说: “你 是最后一名洗完手的, 你来把毛巾架推到阳台上吧!” 幼儿: “啊！我自己推啊。” 教师: “对呀, 我相信你能完成的。” 幼 儿偷偷笑着推走毛巾架。其实这位幼儿内心是愿意推毛巾架 为大家服务的, 但正是因为教师的这项规定, 使幼儿为了达 成目的不得不去触犯规则, 接受他所想要惩罚。

这样的现象不仅出现在幼儿阶段, 学生时代也是如此。 例如教师发布规则: 如果上课说话, 就下楼打扫卫生。有的 学生故意说话, 引起教师的注意, 从而心满意足的下楼了。这 种现象无非是遵循了这样一条规律: 教师制定规则, 提出惩 罚方式一一学生故意违反规则, 接受惩罚——学生达成目 的。我们也可以将其看作是儿童要的 “小聪明”。

但不可否认的是, 这种 “小聪明” 可能会对儿童带来负 面的影响。当他们的 “小聪明” 达成后, 即使会被别人批评, 甚至会被当做是一种反面事例, 他们也会感到愉悦, 这就促 使儿童下一次更加使用这种 “小聪明” 来达成他们的目的, 这可能不利于儿童形成正确的价值观。反过来看, 儿童行为 的结果并不是坏的, 不管是推毛巾架, 还是打扫卫生, 其实都 是一种为他人服务的行为, 而这样的行为被教师当作一种惩 罚的手段, 也是考虑欠缺的。对于这种能够带来积极意义的 行为, 我们更应该从正面对儿童进行引导。在同样的情况下, 教师制定规则为: 哪位幼儿洗手又快又好, 那么由他来推毛 巾架。哪位同学表现好, 那么由他来打扫卫生, 这样会产生什 么样的结果呢? 那位要 “小聪明” 的幼儿可能会又快又好地 洗完手, 被教师表扬, 高兴地完成推毛巾架的任务, 而且还成 为了其他幼儿学习的榜样。那名故意说话同学也会在自己的 控制监督下表现良好, 取得教师的信任, 在其他同学羡慕赞 许的眼光中完成任务。其实人们都喜欢那种 “被需要” 的感 觉, 当我们通过自己的努力做了对他人有贡献的事情时, 我 们也会感到满足。如果成人从正面的角度进行引导, 可能儿 童就会为了达成目的而积极的努力, 这种努力是正面的, 是 被社会大众所认可的, 也就可以避免儿童要 “小聪明” 所带 


\title{
新课改背景下高中地理教学策略研究
}

\author{
尧光明 \\ 重庆市涪陵第十七中学校 \\ DOI:10.32629/er.v2i9.2057
}

[摘 要] 随着教育的发展, 在新课改的背景下,传统的灌输式教学已经越来越不能满足学生的学习需求。如今,要想提升高中地 理教学的有效性, 教师必须要保证学生的主体地位, 创新教学模式, 加强师生互动, 让学生主动地参与到地理教学活动中, 提升自 己的学习能力和思维能力。只有这样, 学生才能在课堂上获得更多的体验和感悟, 高中地理教学才会充满生机与活力。

[关键词] 高中地理; 教学策略; 新课改

新课改是我国教育的重大举措, 对现阶段的教育教学有 重要的推动作用。在新课改的教育背景下, 高中地理教学必 须要突破传统的教育教学模式, 创新教学方法和手段。让学 生成为学习的主人, 自觉地投入到课堂教学活动中。这样才 能提升学生在课堂的参与度和体验感, 以更好地保证高中地 理教学的效果和效率。

笔者结合多年的高中地理教学经验, 主要提出了四种新 课改背景下高中地理教学的策略。分别为: 重视课堂导入, 营造良好的教学氛围; 引入生活化教学, 强化学生的应用能 力; 采取多样措施, 培养学习和思维能力; 应用信息技术, 促进学生的直观理解。下文将对其进行介绍和探讨。

\section{1 重视课堂导入,营造良好的教学氛围}

导入是课堂教学的首要环节, 也是激发学生地理学习兴 趣, 营造良好教学氛围的前提。良好的导入就如同是一篇悬 疑小说的楔子, 起着突出主题, 营造氛围、引起探究欲望的作 用。根据调查显示, 在大部分优秀的高中地理课堂中, 教师都 非常重视课堂导入对整节课的引导作用。他们会根据具体的 教学目标和教学内容, 采取学生感兴趣的方式, 激发学生的
学习兴趣, 为之后的课堂教学奠定基础 ${ }^{[1]}$ 。

如在教学《自然界的水循环》这节课时, 教师可通过李 白《将进酒》中的一句话 “黄河之水天上来, 奔流到海不复 回。” 来引起学生对水循环的思考, 从而导入课堂教学的。再 如在教学《常见的天气系统》这节课时, 教师可通过与学生 进行日常生活的谈话而导入课堂教学的, 即: 昨天哪位学生 收看天气预报了? 今天天气怎么样? 今天的天气与前两天 相比如何? 通过这样的方式, 可以有效地打开学生的话匣子, 让学生全身心的投入到课堂教学中。

\section{2 引入生活化教学,强化学生的应用能力}

地理是一门与生活息息相关的学科, 在生活中有很多自 然现象都需要通过地理知识来进行解释。如自然灾害、农业 生产、区位选择、太阳活动等。因此, 教师在地理教学的过 程中, 应积极地将地理与生活紧密的结合在一起, 让学生在 地理课堂中感受生活, 在生活中学习地理知识。这对于提升 学生的地理应用能力, 培养学生一双善于发现生活中地理问 题的眼睛有重要的意义 ${ }^{[2]}$ 。

如在教学《农业的区位选择》这节课时, 教师可先以一
来的负面影响, 他们也会认识到自己努力做好, 就有机会发 挥自己的价值。

在生活中还有这样一种类似的现象。雨后, 路面不平整的 地方存在积水, 坑坑洼洼, 这时带着孩子的家长往往习惯性地 提醒孩子: “看着脚下, 小心, 不要踩水坑。” 而这时孩子反而 会一脚一脚重重的踩进水坑的中央, 看着水花从脚下飞浌起 来, 家长又是慌忙劝导: “说着不让你踩水坑, 你怎么还故意踩 进去啊。” 其实, 家长的提醒反而是引起了孩子的关注和兴趣, 关注到了雨后地面上会有了一个个的小水坑, 激起了孩子的 好奇心, 为什么不能踩水坑呢? 踩了会有什么样的结果呢? 我偏要试一试。就这样, 造就了家长眼中 “不听话” 的孩子。

但我们尝试在同样的情况下, 家长的表述有所不同, 对 孩子说的话中没有 “不”, 而是从正面引导孩子, 那会是怎样 呢? 雨后, 路面不平整的地方存在积水, 坑坑洼洼, 这时带着 孩子的家长提醒孩子: “你看, 地面上出现了好多的小河沟啊, 我们来比一比赛, 看看谁能够想办法跨越它!”这时孩子会想
尽各种办法, 大步的跨越、踮起脚尖走平地, 或是借助路边的 砖头, 总之, 他们会集中注意力于 “跨越小水沟” 的比赛中, 这时家长自然不必担心孩子故意踩水坑而弄脏鞋子了。有时, 我们转变说话方式, 尽量少对孩子说 “不XX”、“不要XX”、“别 $X X ”$, 从正面以一种积极鼓励的态度教育儿童, 或许会带来不 一样的效果。

总之, 我们对儿童的教育要多从正面的角度出发, 不要 带有一种惩罚或警告的性质, 而是多鼓励、多表扬, 并相信儿 童可以做好, 以此来促进儿童的健康成长。

\section{[参考文献]}

[1]黄静.幼儿园生活化课堂的构建 [J]. 学前教育研 究, 2017,(03):67-69.

[2]张冯青,张思思.幼儿园传统文化教育生活化浅论 [J]. 南昌教育学院学报,2017,32(01):115-116+128.

[3]孙小玉.幼儿园美术教育生活化的策略应用[J].美术 教育研,2017,(14):158. 